\title{
Analysis of Errors in the Transcription of Simple English Vowels (Monophthongs) by Egyptian Phonetics Students
}

\author{
* Dr. Iman M. Mahfouz
}

\begin{abstract}
Raising learners' awareness of the target language phonology is one of the aims of foreign language teaching. Phonetic transcription has traditionally been used in language teaching particularly at advanced levels. This study examines the phonemic transcription of 22 English words by a number of 60 Egyptian learners studying an introductory phonetics course at undergraduate level. It attempts to find out the errors made by students in transcribing English words involving vowels in particular. It also seeks to explain the reasons for these errors, with the aim of raising learners' awareness of them. The study touches upon the deeper underlying structures involved in learning phonemic transcription. Identifying the most frequent errors in phonemic transcription by Egyptian learners of English can help place more emphasis on them in teaching, thus helping the learning process to be more successful.

Keywords: Error Analysis (EA) - phonemic transcription -transcription errors - transcription of simple English vowels
\end{abstract}

* Lecturer and Vice Dean for Education Affairs

College of Language and Communication (CLC)

Arab Academy for Science, Technology and Maritime Transport

(AASTMT) Alexandria 


\section{Introduction}

Phonetic transcription is defined by Wells (2006) as "the use of phonetic symbols to represent speech sounds" (p. 1). There are two main types of transcription: phonemic or broad transcription which distinguishes between phonemes and uses the simplest possible set of symbols, as opposed to phonetic or narrow transcription which is detailed enough to capture the difference between allophones using more specific symbols (Wells, 2006; see also Ladefoged \& Johnson, 2011).

Since raising learners' awareness of the target language phonology is one of the aims of foreign language teaching, phonetic transcription has traditionally been used in language teaching particularly at advanced levels. Lintunen (2005) has found that phonetic transcription errors correlate to a large extent with learners' pronunciation errors. According to Sonning (2013), teaching phonetic transcription becomes all the more beneficial to learners whose first language (L1) has a close grapheme-phoneme correspondence which is lacking in the language they learn (L2). Since the relationship between spelling and pronunciation in English is not straightforward for Egyptian learners, phonetic awareness is thus assumed to improve learners' pronunciation skills (Lintunen, 2005). According to Atkielski (2015) phonetic transcription helps learners better understand their pronunciation errors as it represents them visually. 
Gimson (1970) defines vowels as a "category of sounds ... normally made with a voiced egressive airstream, without any closure or narrowing such as would result in the noise component characteristic of many consonantal sounds" (p. 35). That is, vowels are produced with no obstruction in the vocal tract. They are described in terms of two phonetic parameters: vowel quality and quantity. Quality is determined by tongue height, backness and lip-rounding (Rogers, 2000). In terms of quantity, vowels can be divided into short and long vowels, in addition to diphthongs (Roach, 2004). Gimson also distinguished pure vowels (monophthongs) from those that involve a glide from vowel to another (diphthongs) (Cruttenden, 2014).

English and Arabic, as two genetically different languages, share some common features, but display even more mismatches. These dissimilarities between a learner's L1 and L2 pose difficulties to the learning process. In English, there are 24 consonants and 20 vowels, of which 12 are simple vowels (monophthongs) which are written with only one vowel symbol, and include both short and long (Rogers, 2000). The length mark ' $:$ ' is usually used to designate long vowels in transcription. There are also 8 diphthongs which consist of a glide from one vowel to another (O'Conner, 1980). This study will be concerned only with simple vowels which are shown in the chart in figure (1). 
Figure 1: RP simple vowels (Rogers, 2000)

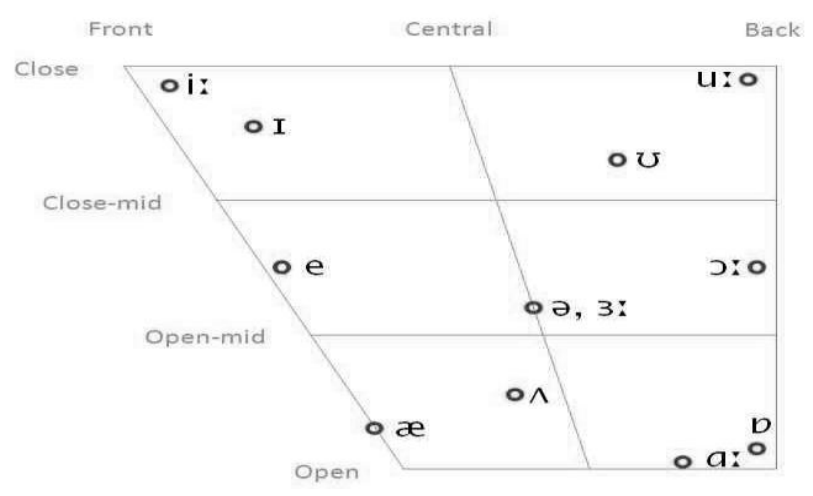

Modern Standard Arabic (MSA), on the other hand, has 28 consonants and only 6 vowels. The vowels include three short ones:

- /i/ nearly close, front, spread

- /a/ nearly open, front, neutral

- /u/ nearly close, back rounded

Each of the above has a long counterpart, /i:/, /a:/ and / $\mathrm{u}: /$, thus constituting a total of six Arabic vowels organized in a triangular system (Bani Salameh \& Abu-Melhim, 2014). It is worth mentioning, however, that short Arabic vowels are not spelt out in writing and can only be shown using diacritics which are seldom used except in special cases, such as for disambiguation or in highly formal or religious texts. 
Figure 2: The vowels of MSA

(Bani Salameh \& Abu-Melhim, 2014)

i:

$\mathrm{u}:$

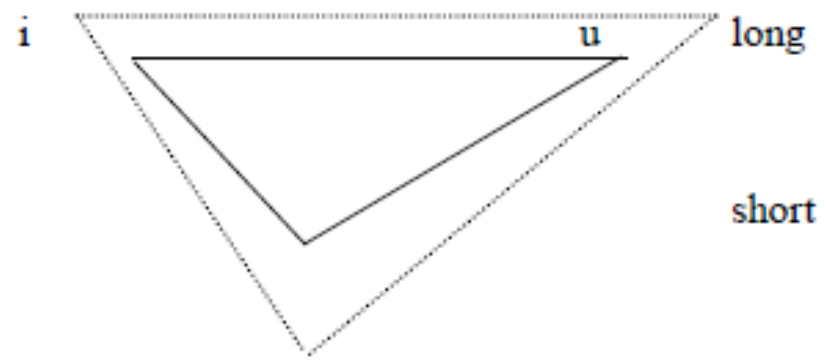

a

Arabic is thus a consonant-heavy language compared to English, with four more consonant phonemes and 14 fewer vowel ones. Since the English vowel inventory is much more complex than the Arabic one, Arab learners who have not received sufficient training in English pronunciation may tend to replace English vowels with their own Arabic ones. When learners are exposed to the set of English vowels, they do not tend to perceive them as a native speaker (Al-Badawi \& Salem, 2014). That is, the six Arabic vowels are mapped onto the set of 20 English vowels.

Having been exposed to traditional education which usually identifies English vowels as 'a, e, i, o, u', learners may be overwhelmed when introduced to English vowels phonetically. They are intrigued when they have to discern 20 English vowels which are the result of different spelling combinations of just a few graphemes. This is compounded by the aforementioned discrepancy between English and 
Arabic vowel systems which is likely to trigger errors in learners' transcription. The present study thus aims to examine the phonemic transcription provided by Egyptian learners for English vowels using a sample of 22 English words transcribed by a number of 60 Egyptian learners studying an introductory phonetics course at undergraduate level. It attempts to find out the errors made by students in transcribing simple English vowels. It also seeks to explain the reasons for these errors, with the aim of raising learners' awareness of them. The study touches upon the deeper underlying structures involved in learning phonetic transcription. Identifying the most frequent errors in phonemic transcription by Egyptian learners of English can help place more emphasis on them in teaching, thus helping the learning process to be more successful.

\section{Review of the literature}

Richards (1973) stated that error analysis (EA) is the study of errors made by second and foreign language learners in order to find out how a person learns a language and obtain information on common difficulties in language learning, as an aid in teaching or in the preparation of teaching materials. EA bears importance to the researcher, teacher as well as to language learners, as it serves to identify areas of difficulty for learners (Corder, 1967). Observing learners' strategy and learning process in this way thus enables placing special emphasis on problematic items in the teaching process as well as developing errorbased teaching material (Huang, 2002). 
Corder (1967) distinguished between an error and a mistake. The former is systematic and comes as a result of linguistic incompetence, whereas the latter is not systematic and may result from transient factors such as fatigue or slips of the tongue. According to the behaviorist theory, learners' errors occur due to interference from the first language (L1). Similarities between L1 and L2 contribute to positive transfer, whereas differences account for negative transfer (Jabeen, Kazemian \& Shahbaz, 2015).

It is worth noting that errors due to language differences are not the only cause of errors, since some errors also arise from other factors, such as universal underlying structures, as well as learners' recognition or the structure of the target language itself. According to Richards (1971), many errors arise not from interlanguage or L1 interference but from intralanguage. These developmental errors "reflect the general characteristics of rule learning, such as faulty generalization, incomplete application of rules, and failure to learn conditions under which rules apply" .(Richards, 1971, pp. 5-6).

The inconsistency of English spelling also contributes to pronunciation difficulties (Cruttenden, 1994). Several letters can stand for the same vowel and the same letter can stand for different vowels. According to Ladgefoged and Johnson (2011), transcribing English vowels is more difficult than transcribing English consonants. This is partly because English vowels vary across accents and also due to the lack of consensus on vowel description. They maintain that "one of the principal problems in transcribing 
English phonetically is that there are more vowel sounds than there are vowel letters in the alphabet" (p. 40). A case in point is the letter "o" in the words some, move, home and women which corresponds to the vowels $/ \Lambda /$, /u:/, /ov/, /I/ respectively. By contrast, faced by the different spelling of the words book, butcher, could, and wolf, learners may be inclined to produce a different vowel quality for the same vowel $/ \mho /$ under the influence of orthography. As Hassan (2014) stated 'correspondence between orthography and phonology enables the students to predict the pronunciation of words from their spelling" (p. 5). He also pointed out that the problem is all the more obvious in the case of unfamiliar words.

El-Hassan (1994) noted that the schwa /ə/ is the most common vowel in English, yet one of the most difficult for Arab speakers primarily due to its intermediate indistinct quality that is not easy to capture. He found that Arab speakers tend to replace this mid-central vowel with other vowels depending on how it is orthographically represented, e.g., with an open front vowel close to /a/ in the first syllable in specific and a close back rounded vowel $/ \mathrm{u} /$ in the second syllable in memorable.

Hassan (2014) also lists the following problems Arab speakers experience with simple English vowels:

- $/ / /$ and /e/ are confused, e.g., sit and set

- $/ \mho /$ and /o/ are confused, e.g., books and box

Several studies have undertaken an error analysis of Arab and Egyptian learners' pronunciation using a transcription of their speech (Bayoumi, 2013; El-Zarka, 2013; Hassan, 2014; Alfehaid , 2015; Hago \& Khan, 2015). 
Kopczyński and Meliani (1993) compared English and Arabic vowel systems and pointed out possible areas of problems to Arab learners of English based on the mismatches involved. They stated that Arab learners perceive and produce English opposition in terms of length. Similarly, Hassan (2014) remarked that the main problem for Arab learners "lies in the establishment of qualitative oppositions" (p. 4). Studies have shown that training adults on perceiving and discriminating phonetic contrasts not existent in their native languages can eliminate learner errors. However, an error analysis of the phonemic transcription produced by Egyptian learners of English themselves, rather than transcribed by the researcher, is still a fertile area of study.

Mahfouz (2016) examined the phonemic transcription of 60 Egyptian learners studying an introductory phonetics course at undergraduate level in order to find out the errors made by students in transcribing English consonants. The study suggested that errors mainly arose from developmental factors, including overgeneralization, ignorance of rules, as well as mutual interference of items in the target language itself, rather than pronunciation difficulties faced by Egyptian learners of English. However, training has so far focused on consonants; little research has been done so far on the perception of vowels, particularly by Arabic speakers (Al-Badawi \& Salem, 2014). The present study thus attempts to explore transcription errors by Egyptian students where simple vowels are concerned. 


\section{Sample and methodology}

A list of 22 individual words was given to a number of 60 first-year students studying an introductory phonetics course in order to transcribe. The list of words was prepared in such a way to ensure covering all 20 English vowels. They included a total of 32 vowels. The list included both monosyllabic (12) and disyllabic words (10) to suit the level of students at this introductory stage. The list of words along with their transcription is found in table 1. Alternative transcription in both RP and GA are provided were applicable. Phonemic transcription will be used for simplicity since students are more familiar with it at this introductory stage.

For simplicity, phonemic or broad transcription was used rather than phonetic or narrow transcription (Roach, 1983). Stress marking was not required.

Table 1: The list of words transcribed by students

\begin{tabular}{|c|c|c|c|}
\hline Word & Transcription & Word & Transcription \\
\hline $\begin{array}{l}\text { 1. dog } \\
\text { 2. man } \\
\text { 3. door } \\
\text { 4. world } \\
\text { 5. switch } \\
\text { 6. book } \\
\text { 7. run } \\
\text { 8. walk } \\
\text { 9. jeans } \\
\text { 10. thrift } \\
\text { 11. pledge }\end{array}$ & $\begin{array}{l}\text { /dog/ } \\
\text { /mæn/ } \\
\text { /ds:/ } \\
\text { /w3:ld/ } \\
\text { /swit// } \\
\text { /bok/ } \\
\text { /ran/ } \\
\text { /wo:k/ } \\
\text { /dzi:nz/ } \\
\text { /Orift/ } \\
\text { /pledz/ }\end{array}$ & $\begin{array}{l}\text { 12. few } \\
\text { 13. measure } \\
\text { 14. vessel } \\
\text { 15. easy } \\
\text { 16. bother } \\
\text { 17. morning } \\
\text { 18. party } \\
\text { 19. cheering } \\
\text { 20. curser } \\
\text { 21. justice } \\
\text { 22. vision }\end{array}$ & $\begin{array}{l}\text { /fju:/ } \\
\text { /mezə/ } \\
\text { /ves }{ }^{2} \text { l/ } \\
\text { /i:zi/ } \\
\text { /boðə/ } \\
\text { /mo:nın/ } \\
\text { /pa:ti/ } \\
\text { /tfırın/ } \\
\text { /k3:sə/ } \\
\text { /dznstıs/ } \\
\text { /viz }{ }^{2} \mathrm{n} /\end{array}$ \\
\hline
\end{tabular}


The subjects of the present study are first year students at the College of Language and Communication (CLC) at the Arab Academy for Science, Technology and Maritime Transport (AASTMT). They study an introductory phonetics course which introduces them to English phonemes and broad phonetic transcription. The class meets twice a week for a 90-minute session. The course also touches upon suprasegmental features, including tone groups, stress and intonation. Students come from a variety of backgrounds, most of whom had English as their first foreign language in their secondary education, although with very little knowledge of English phonetics and phonology if any.

The research follows the procedure suggested by Corder (1974) for error analysis:

1. Selection: collecting samples of learners' language

2. Identification: determining the errors in the selected sample

3. Categorization: categorizing errors into groups

4. Explanation: accounting for the errors

5. Evaluation: interpreting the tables, graphs and conclusions

Transcription was administered in class and monitored by the researcher. Students did not have access to dictionaries or any other source of information while transcribing in order to measure their transcription skills without any interference. Transcription was carried out using the IPA revised to 2015 (The International Phonetic Association, 2015), the most widely used alphabet for phonetic 
transcription (Wells, 2006) and the one taught to the participants of the present study.

Students' transcription was examined with respect to errors in the transcription of simple vowels. Errors were identified by comparing their answers to the transcription of the sample words given in Cambridge Dictionary Online. Students were asked to transcribe the given words in RP (Received Pronunciation), as this is the accent taught in the course and presented in the textbook. A typology of errors was then created according to the four following categories (Corder, 1967):
1. Substitution
3. Addition
2. Omission
4. Ordering

The study attempts to answer the following questions:

1. Which errors involving vowels are recurrent in learners' transcription of English words?

2. Can these errors be accounted for systematically?

3. Do the errors correlate with common pronunciation difficulties or errors of Egyptian learners of English?

\section{Data analysis}

Students' transcription was examined for errors in vowel transcription and a typology was created according to the four categories mentioned above. Creating an error typology was not a straightforward task, since some errors overlapped and some were not easy to categorize. Errors occurring in students' transcriptions can be categorized according to their 
origin (Sönning, 2013). Systematic errors include transfer phenomena, developmental errors and mixing of British and American standards. Less systematic errors are typically due to unknown lexemes or carelessness. In transcriptions of written texts, orthography-induced errors usually reflect graphemephoneme transfer or wrong inferences from ambiguous spellings. The relative frequency of an error was calculated as follows (Huang, 2002):

\section{Relative frequency of occurrence of an error}

$=$ number of actual occurrences of an error

number of possible occurrences of an error

\subsection{Substitution errors}

Substitution errors were found to pose a major problem not only due to the vast number of errors in general, but also due to the numerous alternatives used for each vowel. Several substitution errors were found with almost all vowels. Surprisingly, several vowels were substituted for each other with no specific pattern observed, i.e., the alternatives did not have certain properties in common and included vowels of far different characteristics than the substituted one. For instance, the schwa was replaced with a whole host of vowels ranging from short ones /e, $\mathrm{b}, \Lambda, \mathrm{l}, \mathrm{v} /$ to the long vowel /i:/ and the diphthong $/ \mho ə /$, which all differ in height, backness as well as liprounding. The vowel $/ 1 /$, on the other hand, was mostly replaced with unrounded vowels, such as /e/ and $/ \mathrm{i}: /$, but never with rounded vowels. It was also sometimes replaced with the palatal glide /j/ or even 
the character " $y$ " due to the influence of orthography. Similarly, /i:/ was $n$ turn substituted with /e/ and /1/.

The vowel with the largest number of alternatives used for substitution was / $\mathrm{J}: /$ (15 alternatives), which was found especially problematic (it displayed errors by almost half the participant in the sample). The figure below shows the range of alternatives used to represent this vowel.

\section{Figure 3: The transcription of / $\mathrm{J}: /$}

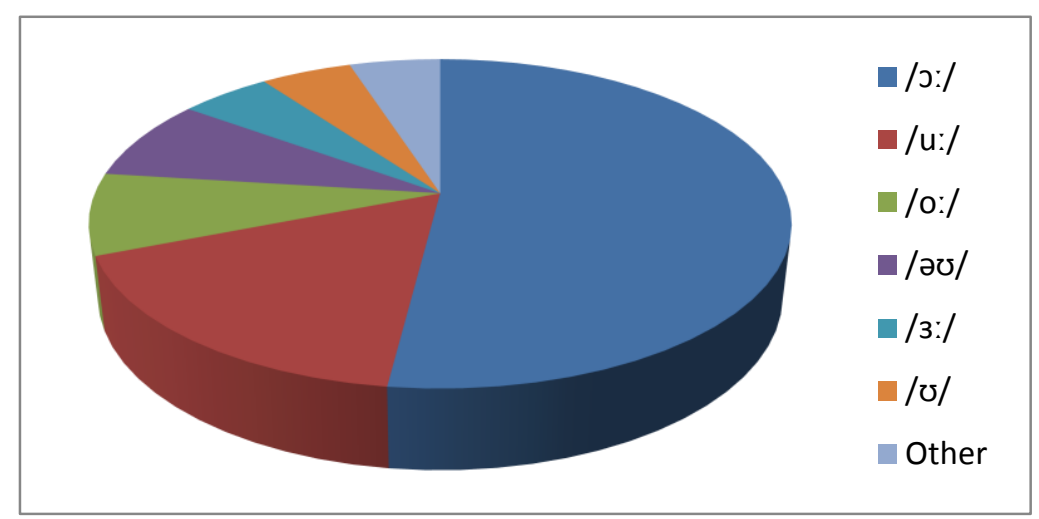

Other vowels which displayed recurrent substitution errors include $/ \Lambda /$ and /ə/ (10 alternatives). Only less than $6 \%$ of the participants made substitution errors involving the vowel /i:/, although they substituted a considerable number of alternatives for it (9 alternatives). The vowels / / and /3:/ were also among those frequently substituted. The only vowel which was not subject to any substitution errors was /u:/. 
Figure 4: Number of alternatives substituted for vowels

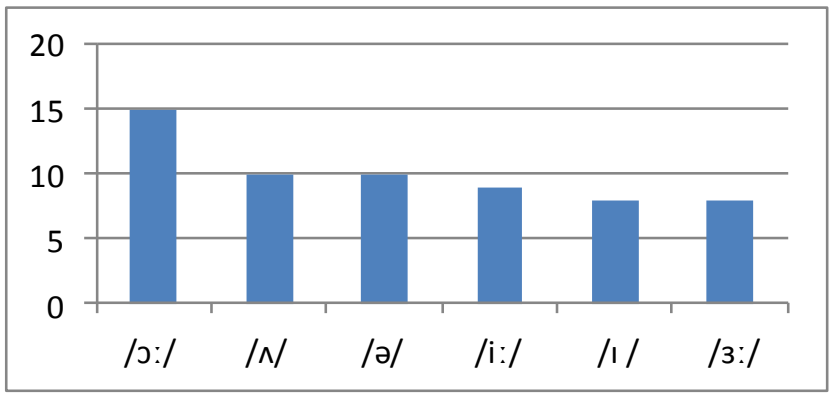

A considerable portion of substitution errors was triggered by the influence of orthography; learners simply copied the grapheme rather than transcribed the phoneme. This sometimes even resulted in characters not existing in the English vowel inventory altogether. The neutral vowel /3:/ as in curser, which is commonly reported to be problematic for Egyptian speakers who tend to replace it with a rounded vowel, was subject to recurrent substitution errors. Since it is spelt as ' $u$ ' in this instance, it was transcribed as a $/ \Lambda /$ by more than $30 \%$ of the students. Other alternatives for this vowel occurring due to grapheme transfer include /u/ (5\%) and / $/$ / (3.3\%). Similarly, the vowel at the end of party and easy was transcribed as ' $y$ ' by $11.7 \%$ of the participants and as the palatal /j/ by $3.3 \%$. 
Table 2: Orthography-induced substitution errors

\begin{tabular}{|c|c|c|c|}
\hline Vowel & $\begin{array}{c}\text { Character(s) } \\
\text { used to } \\
\text { replace it }\end{array}$ & Vowel & $\begin{array}{c}\text { Character(s) } \\
\text { used to } \\
\text { replace it }\end{array}$ \\
\hline$/ \Lambda /$ & "u" & $/ \mathrm{i}: /$ & "ee", "ea" \\
\hline$/ æ /$ & "a" & $\begin{array}{c}\text { /כ:/, } \\
/ \mathrm{p} /\end{array}$ & "o" \\
\hline$/$ / & "e", "io" & $/ 3: /$ & "u" \\
\hline
\end{tabular}

Some substitution errors, on the other hand, correlated with the aforementioned pronunciation difficulties for Egyptian speakers of English reported by Hassan (1994):

- The vowel /o/ in dog was replaced by / / by $16.7 \%$ of the participants.

- The vowels /I/ and /e/ were substituted for each other by $21.7 \%$ of the participants.

- More than 3\% of the students replaced the /i:/ in jeans with $/ \mathrm{e} /$, coinciding with the common pronunciation of this lexical item which has been borrowed into colloquial Egyptian Arabic.

Several substitution errors consisted in replacing short vowels with their long counterparts and vice versa. For instance, $6.7 \%$ of the students replaced the short vowel $/ v /$ in book with the long /u:/. Similar errors occurred with the pairs / $1 /$ and / $i: /$, as well as $/ \mathrm{p} /$ and $/ \mathrm{O}: /$ (although these pairs differ not only in length but also in vowel quality).

As mentioned earlier, the schwa is known to be a problematic vowel for Arab and Egyptian speakers due to its indistinct quality and different spelling 
representations. This was reflected in the transcription errors in the current study. In words where the schwa was spelt as an " $\mathrm{e}$ ", such as vessel and curser it was frequently transcribed as /e/ by $23 \%$ and $16 \%$ of the participants respectively. This occurred to a lesser extent in words where the schwa was spelt differently, such as vision and measure.

Figure 5: Words where schwa was replaced by /e/

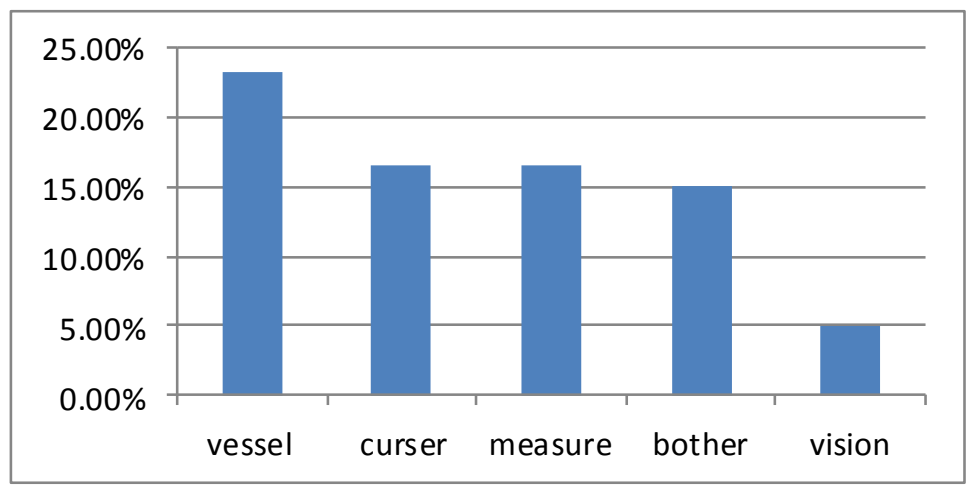

When the schwa was spelt as "io", as in vision, other alternatives also appeared in over $8 \%$ of the cases, mostly the rounded vowels $/ \mathrm{p} /$ and $/ \mathrm{u} /$, in addition to /o/, which does not exist in the English vowel inventory, reflecting the effect of orthography. Likewise, $5 \%$ of the students copied the grapheme in measure and transcribed the schwa as /u/. On the other hand, some substitution errors involving the schwa coincided with common pronunciation errors. Nearly $7 \%$ of the students transcribed the schwa as $/ \Lambda /$ in the words bother, measure and vision, which is in line with a very common pronunciation error among Egyptian speakers of English who tend to replace this mid vowel by a more open vowel. 


\subsection{Omission errors}

Several vowels were subject to omission errors in the transcription sample. It was noticed that short vowels were much more frequently omitted than long ones. Of all long vowels, only /i:/ was omitted although only in less than $1 \%$ of the cases, as opposed to all other long vowels to which a transcription was assigned by students in all instances. The length mark /:/ was omitted by some of the participants in long vowels. This occurred with all long vowels except /u:/, mostly with /a:/ (3.3\%) followed by /i:/ (2.5\%).

The vowel / / was the most frequently deleted in student's transcription (19\% of the cases), compared to only less than $1 \%$ for the long counterpart /i:/. Surprisingly, more than half the students omitted the $/ 1 /$ in the second syllable of cheering $(58 \%)$ and half the students did the same in morning (50\%) with no clear explanation. A possible reason could be that they assume the presence of the velar nasal $/ \mathrm{h} /$ suffices to represent the suffix "ing", so they overlook the vowel in this syllable. The vowel /1/ was also deleted by around $7 \%$ of the students in justice and switch.

This was followed by the schwa which was omitted in almost $8 \%$ of the cases. As a minimal vowel and one of the most problematic to learners, the schwa contributed a significant portion of omission errors. The schwa was omitted most frequently in both vessel and vision, since it is already optional in these two words due to the syllabic / $/$ and $/ \mathrm{n} /$ respectively (with the optional schwa shown as a superscript in the transcription provided by the dictionary). In these two cases, schwa omission was not thus considered an 
error. It was also omitted in other words, especially when spelt as " $\mathrm{e}$ " and to a lesser extent when spelt otherwise, as in measure.

Figure 6: Schwa omission in transcription

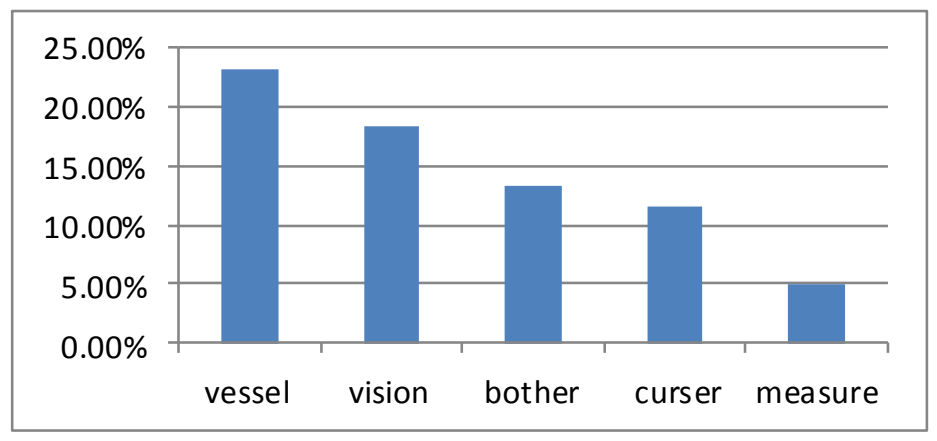

Other vowels were rarely omitted, especially the long vowels /a:/ and /3:/. It was found that the rounded vowels /u:/, / :/ and /p/ did not display any omission errors whatsoever. Even the short rounded vowel / $\mho /$ showed a very slight percentage of omission errors (only less than 2\%). By contrast, unrounded vowels, such as $/ \mathrm{I}$ and $/ \Lambda /$, were much more frequently deleted, especially neutral vowels like the schwa.

Figure 7: Frequency of omission errors

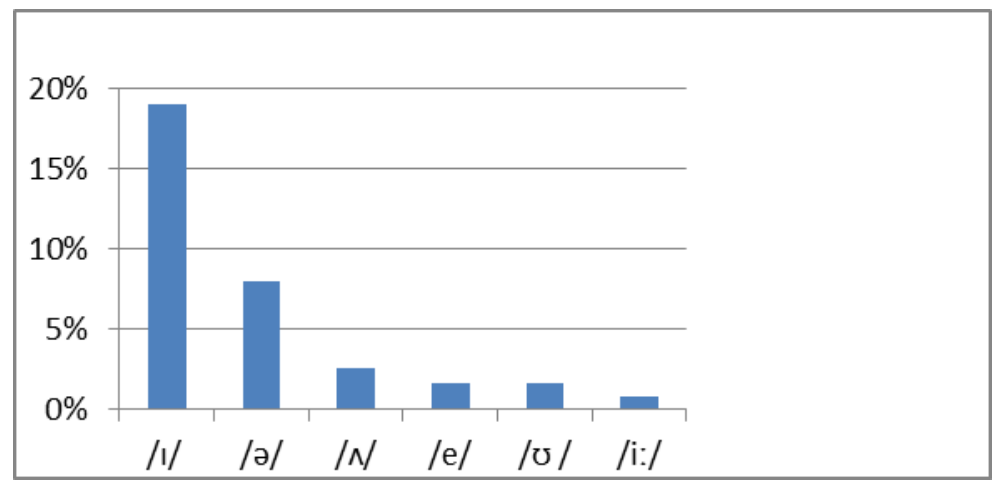




\subsection{Addition errors}

Addition errors were less recurrent in the sample than substitution and omission errors. A large number of addition errors were orthography-induced (nearly $17 \%$ ), especially the addition of /e/ at the end of words ending in a consonant but spelt with " $\mathrm{e}$ " at the end, e.g., sure, justice, measure and pledge. Furthermore, some vowels which are spelt with two characters were transcribed as diphthongs instead of simple vowels. In other words, a second vowel was added resulting in a diphthong where a monophthong occurred. This was mostly due to grapheme transfer in words such as measure and easy. For instance, $20 \%$ of the students transcribed the vowel in the first syllable of measure as a diphthong. In other cases, the result of addition was a diphthong which does not exist in the English inventory. The table below summarizes addition errors resulting in diphthongs instead of simple vowels.

Table 3: Addition errors resulting in diphthongs

\begin{tabular}{|c|c|c|}
\hline Vowel & Addition error & Percentage \\
\hline /e/ & /ea/ & $5.5 \%$ \\
\hline$/ \mathrm{b} /$ & /וכ// & $3.3 \%$ \\
\hline$/ v /$ & $/ \partial v /$ & $1.7 \%$ \\
\hline $\mid$ a & /və, iə/ & $1 \%$ \\
\hline$/ 1 /$ & /aı, el, ıə/ & $1 \%$ \\
\hline / $3:$ / & / 31/ & $0.8 \%$ \\
\hline /e/ & /ea/ & $0.5 \%$ \\
\hline \multicolumn{2}{|c|}{ Total of addition errors resulting in diphthongs } & $10.5 \%$ \\
\hline
\end{tabular}

While some omission errors resulted from removing length from long vowels, a category of addition errors resulted from adding length to short 
vowels. This occurred only with short vowels that have a long counterpart. Sometimes, addition of length was combined with substituting a totally different vowel. In some rare cases, addition was manifested in the form of doubling, mainly of / $/$, which was written as / 1 / for no clear reason.

Table 4: Length addition errors

\begin{tabular}{|c|c|c|}
\hline Vowel & Addition error & Percentage \\
\hline \multirow[t]{2}{*}{ / v / } & / o: , u:/ & $13.3 \%$ \\
\hline & / v: / & $3.5 \%$ \\
\hline$/ 1 /$ & /I:/ & $1 \%$ \\
\hline \multicolumn{2}{|c|}{ Total of length addition errors } & $17.8 \%$ \\
\hline
\end{tabular}

\subsection{Ordering errors}

Possible ordering errors in the transcription of simple vowels can mainly occur due to switching the sequence of vowels and consonants, which would be more likely to occur in longer words than monosyllabic ones. However, ordering errors were very scarce in the transcription sample. The participants in the present study mostly provided the vowels and consonants in the correct sequence within a word. Very few cases (approximately 3\%) were found where order was reversed as in pledge transcribed as /pldze/ where the order of the final consonant and the vowel was reversed. Another case in point was measure which was transcribed as /mezra/ by reversing the order of the schwa and the final $/ r /$. Both cases of ordering errors were orthography-induced since both words ended in ' $e$ '. Otherwise, students managed to maintain the appropriate order of simple vowels within words. 


\section{Findings and discussion}

A wide range of transcription errors was found in the sample. Substitution errors were the most frequent, followed by omission. Addition errors were less frequent and ordering ones were rather rare. In general, it was also noticed that errors occurred more frequently in disyllabic words than monosyllabic ones, suggesting that learners experience more difficulty when transcribing longer or more complex words, even involving the same vowel.

It was not a straightforward task to identify a specific pattern for substitution errors as a very large number of alternatives was substituted for different vowels without clear similarity in vowel characteristics, except for /1/ which was replaced exclusively with unrounded vowels. The vowel displaying the largest number of substitution errors was /כ:/ with numerous alternatives, mostly other rounded vowels, but also including the neutral /3:/ and some diphthongs.

Generally speaking, short vowels displayed a much higher frequency of omission errors than long ones, particularly $/ 1 /$. This may be accounted for on the basis of L1 interference, since short Arabic vowels are not spelt out in writing and can only be shown using diacritics in highly formal or rare contexts. This may explain why students often overlooked this vowel in their transcription, thinking that it is somehow 'underlying'. In fact, more than half of them deleted it when it was part of a gerund, implying that according to their perception, this syllable consisted exclusively of the velar nasal $/ \mathrm{h} /$. By contrast, long vowels were 
rarely omitted. Omission errors for long vowels mainly involved the elimination of the length mark.

Figure 8: Error percentages for short vowels

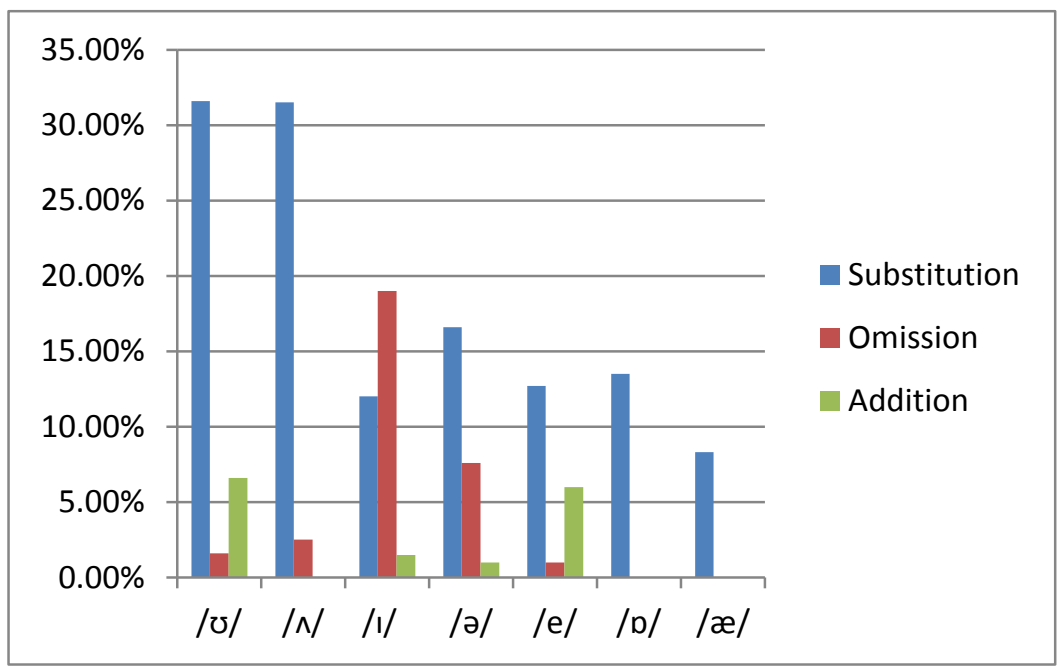

Figure 9: Error percentages for long vowels

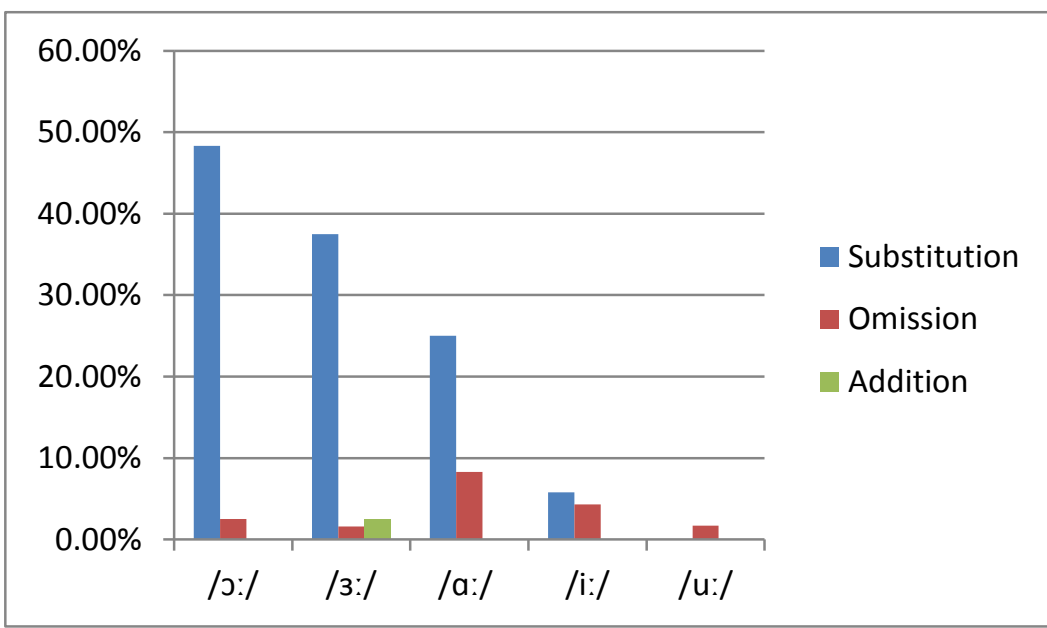

Unrounded and neutral vowels also displayed a higher frequency of omission than rounded ones. As shown in figure (8) and (9), the vowels / $\mathrm{p} /$ and / $/$ :/, for instance, were not subject to any omission errors. The 
length mark was often omitted, turning a long vowel into a short one or resulting in a totally nonexistent short vowel, excluding the vowel/u:/. It may therefore be suggested that rounded vowels possess a more 'distinct' or salient quality that makes them less liable to omission. Nevertheless, rounded vowels still constituted a high percentage of substitution errors, particularly $/ \mho /$ and $/ \mathrm{p} /$.

The schwa, commonly reported to be one of the most problematic vowels for English language learners, especially Arab speakers, expectedly contributed a considerable portion of all types of errors, particularly substitution and omission. A whole host of alternatives was used to replace it and it was frequently either deleted or added unduly. Being a minimal neutral vowel, it was frequently deleted in students' transcription, and since it is manifested in several ways in spelling, it was often subject to grapheme transfer. For instance, when spelt as " $\mathrm{e}$ " as in vessel, it was replaced with /e/ and when spelt as "ion" as in vision, it was either replaced with "io" or with a rounded vowel (see figures 11 and 12 below). On the other hand, some of the errors in schwa transcription coincided with common pronunciation errors when the schwa was replaced with more open vowels. 
Figure 11: Schwa transcription in vessel

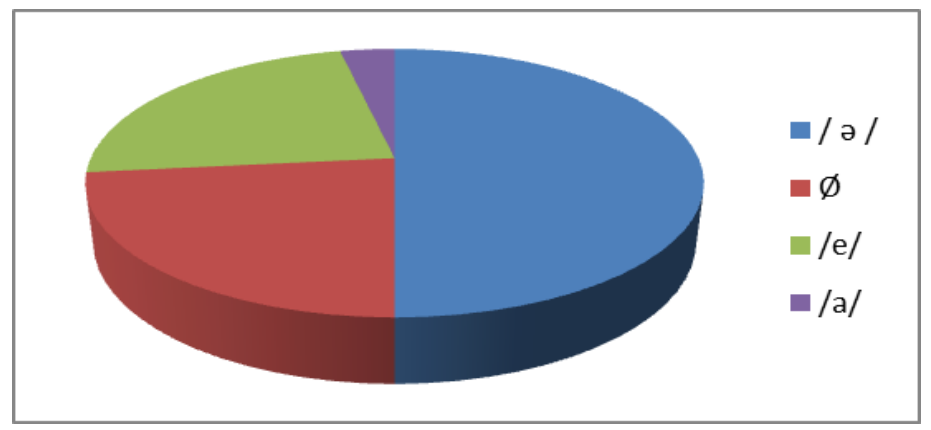

Figure 12: Schwa transcription in vision

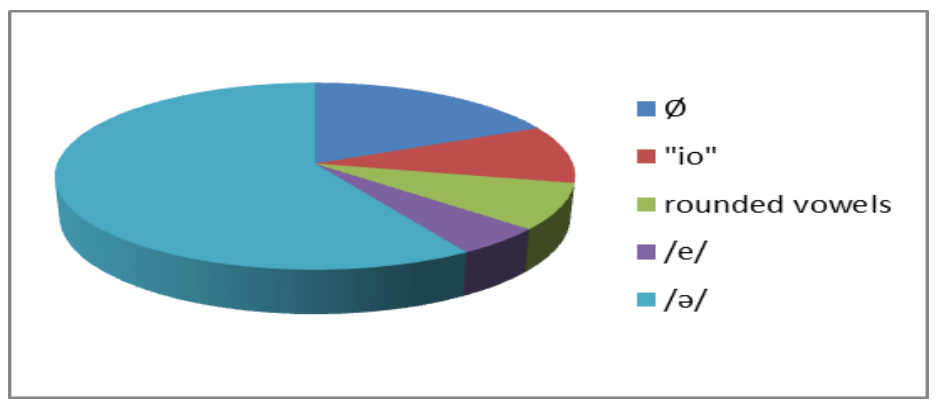

Addition errors were not very systematic, especially those resulting in a non-existent diphthong, i.e., combinations of vowels which do not exist in English such as /eæ/, /3ı/ and /11/. Rather than triggered by L1 interference, these are more appropriately classified as intralanguage errors, since they do not coincide with any L2 counterparts. Developmental or intralanguage errors were also manifested in representing a vowel using characters that do not exist in the English vowel inventory, such as /e:/, /:/ or " $y$ ". By writing some symbols incorrectly, some students revealed their lack of transcription knowledge, e.g., some symbols were written upside down (such as " $v$ " instead of $/ \Lambda /$ ). Several others were 
unable to write the vowel /æ/ correctly and wrote it as the two separate vowels 'ae' instead.

Another category of transcription errors which occurred frequently in the sample was that of orthography-induced errors which accounted for a significant portion of substitution and addition errors. Learners simply copied the grapheme rather than transcribed the phoneme. This sometimes even resulted in characters not existing in the English vowel inventory altogether, thus suggesting that these are intralanguage rather than interference errors.

As for ordering errors, there were very rare in the transcription sample and the very few ones found were orthography-induced. Therefore, it may be said that learners maintaining the appropriate order of simple vowels in relation to the surrounding consonants within a word did not generally constitute a problem for learners, except for cases where grapheme transfer may occur.

Some correlation can be found between L1 interference and errors in the transcription of simple English vowels. The vowel $/ \mathrm{o}$ / and which is not found in Arabic and usually reported to constitute pronunciation difficulties for Egyptian speakers proved especially problematic due to the recurrent substitution it displayed. The schwa was also frequently subject to almost all types of errors. Moreover, some vowel pairs which are usually confused in pronunciation were also substituted for each other in transcription, particularly / $\mathrm{b}, \boldsymbol{v} /$ and /, , e/. Finally, participants often left out short vowels in 
their transcription since it is usual not to spell out short vowels in Arabic orthography.

By contrast, the long vowels /u:/ and /i:/, which are common between participants' L1 and L2 and also spelt out in Arabic orthography, were among vowels with the least error percentages, implying some positive interference. From the above results it may, therefore, be deduced that vowels which do not exist in learners' L1 displayed a much higher error frequency. However, other vowels which are common between the two languages involved intralanguage errors, such as those caused by grapheme transfer as well as inadequate knowledge of transcription conventions.

\section{Conclusion}

Due to the discrepancy between Arabic and English vowel systems, the area of vowel transcription was expected to pose numerous problems to students at an introductory level. Having been exposed to traditional education which usually identifies English vowels as ' $a$, e, i, o, u', students are overwhelmed when introduced to English vowels phonetically. They are intrigued when they have to discern 20 English vowels which are the result of different spelling combinations of just a few graphemes.

The present research has examined the phonemic transcription of 22 English words provided by a number of 60 Egyptian learners studying an introductory phonetics course at undergraduate level. It attempted to find out the errors made by students 
in transcribing simple English vowels. The errors were classified and analyzed with the aim of indentifying the most recurrent and accounting for them. The identification of these transcription errors can hence serve as an excellent basis for preparing instructional materials, course planning and developing actual classroom techniques. In this way, teachers can be made aware of difficult areas or common pitfalls for their students and devote special care and emphasis to them.

It is worth noting that the scope of the study encompassed only transcription errors, since students' actual pronunciation errors were not investigated. The errors included both interlanguage and intralanguage errors. The former category involved vowels not existing in the Arabic vowel inventory and commonly reported to be problematic for Egyptian speaker, whereas the latter category encompassed orthography-induced errors, as well as those related to lack of transcription knowledge. Based on the findings of the present study, practice and remedial exercises and drills should focus on the following areas:

- It would be interesting to examine larger samples of students, especially those with more knowledge of phonetic transcription or studying more advanced courses rather than introductory ones. The use of a larger sample of words may also be recommended in order to confirm the findings of the present research.

- Students' awareness must be raised regarding the common or possible pitfalls encountered by Egyptian learners when dealing with simple 
English vowels. A contrastive approach may be adopted.

- Special emphasis should be given to the transcription of vowels apart from consonants. Separate sessions and exercises may be devoted to transcribing vowels individually before introducing the transcription of whole words.

- More focus should be given to vowels which proved problematic in the course of the present research, such as $/ 0: /, / 3: /$ and the schwa in different positions, as well as the distinction between commonly confused pairs using special exercises and drills geared towards eliminating these errors.

- Transcription conventions and emphasis on the use of IPA consonant symbols without the slightest alteration in their form.

- Neutralizing the effect of orthography and stressing that transcription is mainly concerned with sounds rather than the spelling of words. By establishing a close link between the vowel sound and the corresponding IPA symbol, several problems may be eliminated.

- Since errors were more frequent in disyllabic words than monosyllabic ones, it may be advisable to start transcription practice using shorter words before gradually proceeding to longer ones.

Several types of errors were found in the sample and some were rather frequent, suggesting that further research and attention should be devoted to the transcription of vowels by phonetics students. The 
findings of the present study thus beg for more indepth work in the following research areas:

- Further studies should be conducted on teaching methods designed to eliminate the errors reported by the present study, as well as to improve students' transcription skills in general.

- Similar studies should target errors in the transcription of diphthong which are expected to be even more problematic than simple vowels since they involve vowel combinations.

- More quantitative studies are required to measure the effectiveness of various methods and materials used for transcription teaching and training on different groups of students and their development across the duration of studying.

- Further studies may also tackle errors made by Egyptian phonetics students in terms of other more advanced suprasegmental features, such as stress assignment, syllable division and intonation. 


\section{References}

1. Al-Badawi, M. A. \& Salem, J. A. (2014). The perception of English vowels by Arab EFL learners: A case study of university students at Zarqa University. Research on Humanities and Social Sciences. 4(20). pp. (23-27). Retrieved from http://iiste.org/Journals/index.php/RHSS/article/viewFile/15784/1 $\underline{6578}$

2. Alfehaid, M. (2015, Oct.). Pronunciation problems Arab speakers encounter while learning English. International Journal of Scientific and Engineering Research, 6(10). pp. (58-582). Retrieved from http://www.ijser.org/researchpaper/Pronunciation-ProblemsArab-Speakers-Encounter-While-Learning-English.pdf

3. Atkielski, A. (2005, Dec.). Using phonetic transcription in class. Retrieved from http://digilander.libero.it/mgtund/Phonetics\%20\%20Using\%20Phonetic\%20Transcription\%20in\%20Class. pdf

4. Bani Salameh, M. Y. \& Abu-Melhim, A. (2014). The Phonetic Nature of Vowels in Modern Standard Arabic. Advances in Language and Literary Studies. 5 (4). pp. (60-67). Doi:10.7575/aiac.alls.v.5n.4p.60

5. Bayoumi, A. (2013). Common pronunciation errors in the speech of undergraduate Egyptian students at Ain Shams University and ways of dealing with them.

Retrieved from https://languagers.wordpress.com/2013/09/13/commonpronunciation-errors-in-the-speech-of-undergraduate-egyptianstudents-at-ain-shams-university-and-ways-of-dealing-with-them/

6. Cambridge Dictionaries Online (2016, May). Retrieved from http://dictionary.cambridge.org/ 
7. Corder, S. P. (1967, Nov.). The significance of learner's errors. International Review of Applied Linguistics in Language Teaching. V(4). Retrieved from

http://files.eric.ed.gov/fulltext/ED019903.pdf

8. Corder, S. P. (1974). Error analysis. In J. P. B. Allen \& P. Corder (Eds.). Techniques in Applied Linguistics (The Edinburgh Course in Applied Linguistics). 3. (pp. 122-131). London: Oxford University Press.

9. Cruttenden, A. (2014). Gimson's pronunciation of English. ( $8^{\text {th }}$ ed.). New York: Routledge.

10.El-Hassan, S. (1994). English Accentuation and vowel quality as pronounced by Arabs: A pedagogic statement. Proznań Studies in Contemporary Linguistics. 29, (pp. 205-216). Retrieved from http://wa.amu.edu.pl/psicl/files/29/13El-Hassan.pdf

11.El-Zarka, A. M. (2013, Oct.). The pronunciation errors of L1 Arabic learners of L2 English: The role of Modern Standard Arabic and vernacular dialects transfer. MA dissertation. The British University in Dubai. from http://bspace.buid.ac.ae/bitstream/1234/664/1/90087. pdf

12.Gimson, A.C. (1970). An introduction to the pronunciation of English (2nd ed.) London: Edward Arnold. 
13. Hago, O. E. (2015, Oct.). The pronunciation problems faced by Saudi EFL learners at secondary schools. Education and Linguistic Research. 1(2). (pp. 85-99). doi: 10.5296/elr.v1i2.7783

14.Hago, O. E. \& Khan, W. A. (2015, Oct.) The pronunciation problems faced by Saudi EFL learners at secondary schools. Education and Linguistics Research. 1(2). (pp. 85-99). doi:10.5296/10.5296/elr.v1i2.7783

15. Hassan, E. M. I. (2014, Nov.). Pronunciation problems: A case study of English language students at Sudan University of Science and Technology. English Language and Literature Studies, 4 (4). pp. (31-44). doi:10.5539/ells.v4n4p31

16. Huang, J. (2002). Error analysis in English teaching: $A$ review of studies. Retrieved from http://lib.csghs.tp.edu.tw/\%E4\%B8\%AD\%E5\%B1\%B1\%E5\%A5 \%B3\%E9\%AB\%98\%E5\%AD\%B8\%E5\%A0\%B1\%E7\%AC\%A C\%E4\%BA\%8C\%E6\%9C\%9F/03ERROR\%20ANALYSIS.pdf

17.Jabeen, A., Kazemian, B. \& Shahbaz, $M$. (2015, Sept.). The role of error analysis in teaching and learning of second and foreign language. Education and Linguistics Research. 1(2). (pp. 52-62). doi:10.5296/elr.v1i1.8189 
18. Kopczyński, A. \& Meliani, R. (1993). The vowels of Arabic and English. Papers and Studies in Contrastive Linguistics. XXVII. (pp. 183-192). Retrieved from http://ifa.amu.edu.pl/psicl/files/27/13Kopczynski-Meliani.pdf

19.Ladgefoged, P. \& Johnson, K. (2011). A course in phonetics $\left(6^{\text {th }}\right.$ ed.). Retrieved from: https://bayanbox.ir/view/2038311472801972102/A-Course-inPhonetics.pdf

20.Lintunen, P. (2005). Phonemic transcription and its effect on learning. Retrieved from https://www.ucl.ac.uk/pals/study/cpd/cpdcourses/ptlc/proceedings 2005/ptlcp30

21.Mahfouz, I. M. (2016, Dec.). Analysis of errors in the phonetic transcription of English consonants by Egyptian undergraduate language students. Faculty of Education Journal, Alexandria University. 26(6).

22.0'Conner, J. D. (1980). Better English pronunciation. ( $2^{\text {nd }}$ ed.). UK: Cambridge University Press.

23. Richards, J.C. (1971). A non- contrastive approach to error analysis. Journal of ELT. 25, (pp. 204-219). Retrieved from

http://files.eric.ed.gov/fulltext/ED037721.pdf

24.Roach, P. (1983). English phonetics and phonology: A practical course. UK: Cambridge University Press.

25.Roach, P. (2004). British English: Received Pronunciation. Jounral of the International Phonetic Association: Illustrations of the IPA. 34 (2). doi: https://doi.org/10.1017/S0025100304001768 
26.Rogers, H. (2000). The sounds of language. England: Pearson Education Limited

27.Sönning, L. (2013). Scrabble yourself to success: Methods in teaching transcription. Proceedings of the Phonetics Teaching and Learning Conference, J. Przedlacka \& and J. Maidment (Eds.). (pp. 83-86). Retrieved from http://wa.amu.edu.pl/kdk/sites/default/files/proceedings_2013.pdf

28. The International Phonetic Association (2015). The International Phonetic Alphabet (revised to 2015). Retrieved from https://www.internationalphoneticassociation.org/sites/default/file s/IPA_Kiel_2015.pdf

29.Wells, J. C. (2006). Phonetic transcription and analysis. In Encyclopedia of Language and Linguistics. Retrieved from http://www.phon.ucl.ac.uk/home/wells/transcription-ELL.pdf. 